\title{
ECO-FRENDILY DYEING AND FINISHING ON SILK FABRIC
}

\author{
Priyadarshini $\mathbf{A}^{\mathbf{1}}$, Vasugi Rajaa ${ }^{2}$ \\ ${ }^{1}$ Assistant professor, Department of PG Studies and Research in Home science, J.B.A.S College for Women, \\ Chennai-18., Tamilnadu, India \\ ${ }^{2}$ Professor and HOD, Department of Textiles and Clothing, Avinashilingam University, Coimbatore. Tamilnadu, \\ India
}

\begin{abstract}
Today in the world of eco-friendly textiles, it becomes very important to solve the water pollution problem. Most of the textiles effluent came from dyeing industries spoil the water source and carcinogenic dyes create skin diseases and environmental hazards. So the present study focuses on plasma treatment, dyeing and fragrance finishing using natural sources. Plasma treatment is increase the dye uptake and luster in the silk fabric without more water consumption. Plasma treatment stands for, energy efficient, water saving, and economic than classical textile finishing processes. Traditional textile wet process needs lots of water to reduce the water consumption plasma treatment is used for surface modification of silk fabric. Plasma is a dry process is done by gases. Onion skin is a good dye yielding and antimicrobial source. These kind of natural sources are best alternative for synthetic dyes because these dyes are nature friendly dyes. Fragrance finish is a process where the substrate is subjected to inclusion of fragrance or essential oil which gives effects such as sedation, hypogynies, curing hyper tension. A new branch of textiles called "Aromatherapy textiles", involves the incorporation of these essential oils on the textiles substrate for daily use.
\end{abstract}

Key words: Plasma treatment, Silk fabric, Natural dye, Fragrance finishing,

\section{INTRODUCTION}

The public attentiveness allied to environmental problems have led the textile industry to manufacture products with environmental friendly profile[1] silk the queen of textiles is distinguished for luxury, elegance and comfort.silk is produced by the silkworm bombyx mori; it is the only organic fiber that is in the form of filament. Silk has been defined as "smooth, lustrous, elastic fiber of small diameter and of animal origin"[2]. Plasma is a Greek origin word meaning 'collective'. It can exist over an extremely wide range of temperature and pressure, some scientist has dubbed plasma as "the fourth state of matter", because the plasma is neither gas nor liquid, its properties are similar to those of both gases and liquids plasma can be defined as a partially or wholly ionized gas with a roughly equal of positive or negative charged particles in enticed states, radicals, metastables and vacuum ultra violet radiations[3].

The importance of color in textile has been recognized from thousands of years; ancient writing contains frequent references for it, India has the distinction of being a color box of the ancient world in the past presumes [4].many of the natural dyes used render color as well as anti-microbial properties to the fabrics[5]. Some such dyes or plant parts which provide such dual properties can be named as pomegranate peel, babool, walnut rind, onion skin. Fragrance finish prevents the fabric from body odour after long use. It makes the garment as well as environment fresh. Apart from fragrance it also imparts softness to the fabric [6]

\section{MATERIALS AND METHODS}

\subsection{Materials}

Silk is the strongest natural fibre at 2.6 to 4.8 grams per denier. Five meters of mulberry silk fabric was purchased from khadhi shop in Coimbatore for this study. Onion skin is a member of the allium family. The onion's dry papery skin called Quercetin, which is one kind of flavonids, it gives the brownish Orange color. These are usually thrown as a waste. The dried skin was collected and it was used as a natural dye source.

\subsection{Procedure For Plasma Treatment}

The degummed silk fabric in the dimension of 55centimeter in length and 45 centimeter width of samples was used for plasma treatment. The mechanism used in plasma treatment is glow discharge method. In this study atmospheric pressure plasma reactor was used. Plasma chamber is having acrylic sheet was inside chamber and it is transparent to light. The gap between the two glass plates two millimeters to start the plasma discharge under oxygen gas zone which is working on the principle of glow discharge method. The power needs to generate plasma depends on the size of the electrodes and gap between the electrodes. The application of plasma in the presence of oxygen gas in this chamber the plasma chamber is operating in the flow of oxygen in the rate of 0.15 SLPM (Standard Liter per Minute) and RF (Radio Frequency) discharge was varied between 400w and $700 \mathrm{w}$ for 5 to 6 minutes. Distance between the electrodes where fabric passes through was changed 0.28 to $0.38 \mathrm{~cm}$. 


\subsection{NATURAL DYEING}

\subsubsection{Extraction of Colorant}

100grams of crushed onionskin was added in the boiling water and allowed to boil for 1 hour the same temperature was maintained. Then the dye solution was filtered with whatemen filter paper.

\subsubsection{Selection of Mordanting}

Mordant is considering as an integral part of natural dyeing process to improve the affinity, uptake as well as hue. Few natural dyes are colour-fast with fibres. Mordants are used to fix a dye to the fibres. Alum is easily available and partly less toxic than other metal mordants. Alum as its name suggests, is an aluminum compound, packaged as a white powder. Alum is cheap, easily available and safe to use mordant. Aluminium sulphate (Alum) was selected for this study

\subsubsection{Post Mordanting and Dyeing}

Based on the pilot study post mordanting and dyeing was selected. The degummed silk fabric and plasma treated silk fabric were boiled in extracted dye solution and 2 percent alum at the liquor ratio of 1: 10 boiled for 30 minutes at $100^{\circ} \mathrm{C}$ then fabric was removed and washed thoroughly with clean water.
The plasma treated dyed and finished samples were evaluated visually by a panel of judges. The dyed and finished samples were then tested in the laboratory for fabric weight, tensile strength in comparison with original samples and the results were analyzed statistically. Colour fastness test were carried out for the dyed samples.

\subsubsection{Selection of Finishing Agent}

Sandal wood oil and eucalyptus oil were selected for fragrance finishing and applied on the dyed and plasma treated dyed silk fabric .for this study 25 grams of sandal wood oil and eucalyptus oil were used.

\subsubsection{Padding Mangle Method}

The selected finishing agents were applied using padding mangle techniques. In the machine three rollers with sponch which is rotating on opposite direction techniques. In this machine selected finishing agent was applied on the tray the temperature for curing the fabric will set according to the nature of the cloth and finishing agent .hence the selected temperature were $60^{\circ} \mathrm{C}, 80^{\circ} \mathrm{C}$ and $100^{\circ} \mathrm{C}$,time $30,60,90$ minutes respectively. Pilot study was done for find out the exact parameters needed for finishing after the pilot study, it was concluded that $90^{\circ} \mathrm{C}$ and 6 minutes were chosen for this study

\section{RESULTS AND DISCUSSION}

Table - I. Evaluation of physical properties

\begin{tabular}{|c|c|c|c|c|c|c|c|c|c|c|c|c|}
\hline \multirow[t]{2}{*}{ Properties } & \multicolumn{3}{|c|}{ Original } & \multicolumn{3}{|l|}{$\mathbf{P F}$} & \multicolumn{3}{|l|}{ PDFF } & \multicolumn{3}{|c|}{$\overline{\mathrm{DFF}}$} \\
\hline & Mean & $\begin{array}{l}\text { Gain } \\
\text { /loss }\end{array}$ & $\begin{array}{l}\% \text { of } \\
\text { Gain } \\
\text { /loss }\end{array}$ & Mean & $\begin{array}{l}\text { Gain } \\
\text { /loss }\end{array}$ & $\begin{array}{l}\text { \% of } \\
\text { Gain } \\
\text { /loss }\end{array}$ & Mean & $\begin{array}{l}\text { Gain } \\
\text { /loss }\end{array}$ & $\begin{array}{l}\text { \% of } \\
\text { Gain } \\
\text { /loss }\end{array}$ & Mean & $\begin{array}{l}\text { Gain } \\
\text { /loss }\end{array}$ & $\begin{array}{l}\text { \% of } \\
\text { Gain } \\
\text { /loss }\end{array}$ \\
\hline $\begin{array}{l}\text { Fabric weight } \\
\text { (grams) }\end{array}$ & 0.66 & & & 0.81 & 0.15 & 22.7 & 0.78 & 0.12 & 18.1 & 0.71 & 0.05 & 7.5 \\
\hline Fabric thickness (mm) & 0.14 & & & 0.17 & 0.3 & 21.4 & 0.17 & 0.3 & 21.4 & 0.16 & 0.2 & 12.1 \\
\hline Tensile strength $(\mathrm{Kg})$ & 40.8 & & & 50.6 & 9.80 & 23.4 & 52 & 11.20 & 27.4 & 43 & 2.20 & 5.3 \\
\hline Elongation $(\mathrm{cm})$ & 5.2 & & & 6.2 & 1.06 & 20.3 & 6 & 1.00 & 19.2 & 4.9 & 0.28 & 5.76 \\
\hline Abrasion (grams) & 0.08 & & & 0.10 & 0.02 & 12.5 & 2 & 0.02 & 2 & 0.9 & 0.0 & 1.2 \\
\hline Stiffness (cm) & 1.65 & & & 2.45 & -0.77 & 45.8 & 2 & -0.37 & 22 & 1.5 & 0.18 & 10.7 \\
\hline Crease recovery $\left({ }^{\circ}\right)$ & 126.5 & & & 131 & 5.2 & 4.1 & 135 & 9.4 & 7.4 & 126.8 & 0.6 & 0.4 \\
\hline
\end{tabular}

ORIGINAL - Control sample, PF - plasma treated sample, PDFF -plasma treated dyed and finished sample, DFF - dyed and finished sample

In the visual inspection, the dyed sample was rated as excellent in colour, evenness in dyeing, texture, fragrance.

In the visual inspection, the plasma treated, dyed and finished (PDFF) sample was rated as excellent in colour, evenness in dyeing, texture, fragrance.
The objective evaluation such as weight and thickness were high in plasma treated sample (PF) where as crease recovery, elongation, stiffness, tensile strength, abrasion resistance were higher in plasma treated dyed and finished samples (PDFF) than original sample.

Colour fastness property was rated as excellent in PDFF and DFF samples. The PDFF sample was rated higher than DFF sample. 
It will be concluded that silk fabrics can be enhanced by the application of plasma treatment, natural dyeing and fragrance finishing from the selected source and their performance is highly satisfactory even after repeated washing.

\section{CONCLUSION}

The queen of textiles silk is a wonderful gift of nature. It is a unique product that has fascinated every part of the blue green globe especially Indian women. Fragrance finishing of textiles is the process to enhance the value of the product by adding some incentives to it. Every person desires for some change something new and unique. The successful effective implementation of change has to be done to in the market by value added finish with the incorporation of different fragrance into fabrics, leading to the production of scented fabrics and the psychology of acceptance of natural in textile goods. Plasma treatment of silk fabric increase the luster and dyeablity. Onion skin is easily available dyestuff and reduces waste. The natural dyed and fragrance finished silk fabric can be used to prepare attractive apparel material without creating skin problems

\section{REFERENCE}

[1] Chen L.S [2008], aromachology and its application in the textile field, journal of industrial textiles, January, vol - 32, pg : 263-274

[2] Ninge gowda [2011], a natural colorant from fiche racemes for silk, colourage, september, vol-lvii, pg: 69

[3] Aroras and avita rani, [2007], plasma technology on eco-friendly approach, january, vol no-1, page no:-7-9.

[4] Singh o.p [2005], dyeing wool with natural dyes and natural mordant, january vol -lii, pg : 153-155

[5] Preeti udwat, srivastava and richugupta [2008], ecofriendly dye from marinade citrifolia lin, textile trends, march vol.li no.12, pg-27

[6] Edward menezes, [2005], developments in silk finishing, indian textile journal, march, vol.no:cxv-22, pg-121 